\title{
Performance evaluation of Collaborative Learning and E-commerce Security: Comprehensive Ability of China's PE Teachers to Use Computer
}

\author{
Zhang Yan $^{1}$, Wei Dongyi ${ }^{1}$, Liu Yichong ${ }^{1}$, Long Xiaodong ${ }^{2 *}$ and Tao Ganchen ${ }^{2}$ \\ ${ }^{1}$ Guangxi University of Chinese Medicine, Nanning, Guangxi, China \\ ${ }^{2}$ P.E. Department, Jinggangshan University, Ji'an Jiangxi, China \\ *171761779@qq.com
}

\begin{abstract}
In this paper, we discuss the current situation of the comprehensive computer ability of $P E$ teachers in colleges, and find out deficiencies, then provide valuable theoretical basis for optimized development. A total of 122 PE teachers were selected as the research objects of the network questionnaire during July 2014 and December 2014, and we investigate related data of those teachers, by using reliability and validity test, we find out relationship between their ability to use computers and the basic information. The results shows that the P value of the comprehensive ability to use computers of PE teachers in colleges and universities is less than 0.01 by sex, region, age group, school age, title, educational background structure, highest level of papers published in the past 5 years and the highest level of completed topics within the past 5 year.
\end{abstract}

Keywords: E-commerce; Performance evaluation, PE Teachers, Collaborative Learning

\section{Introduction}

Computer development has been remarkably rapid since the year of 2000 and computer has not become a unique discipline, with strong scientificity, engineering property and practicability. Furthermore, the discipline has closely related theory and practice [1]. For colleges and universities in China, highly competent and highquality teachers are indispensable for enhancement of core competitiveness. Whether the PE teachers are comprehensively able to use computers poses a direct impact on the long-term development of physical education of schools and national fitness of China [2]. For colleges and universities, how to improve the comprehensive ability to use computers of PE teachers in colleges and universities, give full play to their wisdom and constantly enhance their teaching ability and scientific research ability are the keys to contemporary times' development. This paper investigates and analyzes this from the main aspects of comprehensive ability to use computers (information access, network downloading, information processing, multi-media making, form processing, picture processing, data processing and data mining), so as to understand the current situation of the comprehensive ability to use computers of PE teachers in colleges and universities, and, in turn, study the degree of connection between this ability and sex, region, age group, school age, title, educational background structure and scientific research ability (thesis and topics). This way, a series of related problems are discovered.

Then, the limited strategies to realize effective development of comprehensive ability to use computers for PE teachers in colleges and universities are discussed.

* Corresponding Author 
Constant improvement of the comprehensive ability to use computers of PE teachers in colleges and universities is of significant realistic value [3].

\section{Object and Research Method}

\subsection{Study Time and Object:}

The questionnaire lasted for half a year from July 1, 2014 to December 31, 2014; study objects: 122 PE teachers in colleges and universities of Beijing, Shanghai, Jiangxi and Guangxi

\subsection{Technical Line Design of Network Questionnaire}

2.2.1. Scale Design and Establishment of Standards: Before start of the questionnaire, the index scale of comprehensive ability to use computers for PE teachers was appraised by experts. The validity test of expert questionnaire: The structure and content validity test method was used. Test Result Table 1 shows that: Among professors, 3 believed that the validity was very high, 2 believed the validity was high and 1 believed the validity was fair; among associate professors, 3 believed that the validity was very high, 3 believed the validity was high and 1 believed the validity was fair; among the doctors, 1 believed that the validity was very high, and 1 believed the validity was high. To sum up, 7 believed the validity was very high, accounting for $46.677 \%$ of the total; 6 believed the validity was high, accounting for $40 \%$ of the total, and 2 believed the validity was just fair, accounting for $13.33 \%$ of the total. In can be seen that the opinions of the 15 experts were basically the same, which indicates that the content structure was effective and can simply and truly reflect the actual condition of the tested objects. The test results are satisfactory. The reliability test of questionnaires of the 15 experts: The Cronbach a coefficient was used during the research to observe the internal consistency. In this questionnaire, $a=0.9$, coefficient $>0.7$ and the $p$ values are all less than 0.01 [4]. The two rounds of questionnaires are highly related, and the required reliability is met. The 5-score grading system was used for the questionnaire. Five scores indicate a very strong ability; 4 scores indicate a strong ability; 3 scores indicate a fair ability; 2 scores indicate a weak ability; 1 score indicates a very low ability. There are a total of 8 questions, with a total of 40 scores. Specifically, 8 12.99 scores ind icate a very low ability; 13 20.99 scores indicate a low ability; 21 28.99 scores indicate a fair ability; 29 35.99 scores indicate a strong ability; 36 40 scores indicate a very strong ability. The more scores one gets, the higher comprehensive to use computers one has. The "retesting method" was used for the network questionnaire for PE teachers. The correlation coefficient $r$ is respectively $0.95, p<0.01$, and is reliable and confident [5] - [8].

2.2.2. Network System Construction: 1). Overall building: The elements of the network survey system are mutually independent from the top to the bottom. The research objects of this paper generally include the data layer (data on basic information and comprehensive ability to use computes), foundation platform layer (public service platform), application layer (database management system and information reporting system) and business system (data analysis and mining) [9]. 2). Survey of system construction: Survey of system construction is the core of network survey. It is mainly realized through the logic verification module, Ajax transmission module, and backend database memory operation module at the client. 3). Management of system construction: This is mainly based on the ArcEngine 
framework building and aims at maintaining the operation and stability of the system via techniques such as GPRS, MVC and SOA.

Table 1. Expert Questionnaire Validity Test $(n=15)$

\begin{tabular}{|c|c|c|c|c|c|c|c|}
\hline \multirow{2}{*}{ Index } & \multirow{2}{*}{$\mathrm{n}$} & \multicolumn{5}{c|}{ Statistics of Questionnaire Validity Test } \\
\cline { 4 - 8 } & & & Very high & High & Fair & Low & Very low \\
\hline \multirow{3}{*}{$\begin{array}{c}\text { Expert } \\
\text { structure }\end{array}$} & Professor & 6 & 3 & 2 & 1 & 0 & 0 \\
\cline { 2 - 8 } & $\begin{array}{c}\text { Associate } \\
\text { professor }\end{array}$ & 7 & 3 & 3 & 1 & 0 & 0 \\
\cline { 2 - 8 } & Related doctor & 2 & 1 & 1 & 0 & 0 & 0 \\
\hline \multicolumn{2}{|c|}{ Subtotal } & 15 & 7 & 6 & 2 & 0 & 0 \\
\hline \multicolumn{2}{|c|}{ Percent (\%) } & 100 & 46.67 & 40 & 13.33 & 0 & 0 \\
\hline
\end{tabular}

2.2.3. Construction of Database: The first step is to design the database, which is able to store large mounts of valuable information in an effective way. The research network survey database basically includes: database of basic information on PE teachers, database of survey information, and database of survey of comprehensive ability to use computers [10].The second step is to acquire data: Generally, the simple information data reporting survey organization mode with the basic level as the unit is used to acquire required data in a fast and simple way.

The last step is to build the database: The data acquired from the network should be stored, sorted and systemized. The network valid and valuable data of survey should be put in storage to establish the network survey value database.

\subsection{Method of Comparative Analysis}

Comparison is a commonly used thinking method to understand, distinguish and confirm the similarity and difference among different things, so as to reveal the essence of things. This paper tries to understand the difference among the comprehensive ability to use computers of PE teachers through comparison.

\subsection{Mathematical Statistics and Formula Support}

The SPSS18.0 is used to carry out statistical analysis. The measurement data are expressed using the mean, standard deviation, T value and $\mathrm{P}$ value. T-test is used for comparison among groups. The enumeration data are expressed with percentage. The variance analysis is used for research. $\mathrm{P}>0.5$ indicates there is no significant difference or any statistical significance; $\mathrm{P}<0.05$ indicates that there is significant difference and statistical significance; $\mathrm{P}<0.01$ indicates there is very significant difference and statistical significance. The main calculating support formula is: The calculating formula during the mean process is (basic formula): $X=\sum X i / n$; and the calculating formula for estimation of mean is $\mathrm{X}=\mathrm{AM}+\mathrm{n} \sum \mathrm{X}^{\prime} / \mathrm{n}$ [11].

Carry out logical reasoning of the data statistical significance results using methods such as comparison, deduction, induction, analysis and reasoning, so as to draw correct conclusions.

\section{Results and Analysis}

\subsection{The Comprehensive Ability to Use Computers of PE Teachers in Colleges and Universities is Generally Low}

Results in Table 2 indicate that: The mean value of the comprehensive ability to use computers of PE teachers in colleges and universities is 3.50 in terms of information access, and the standard deviation is 1.02. Information accessing is the 
foundation for PE teachers to make improvements. They can access related large amounts of authoritative information on HowNet, Wanfang Database, Baidu and Sogou to strengthen their scientific research and teaching ability; the mean value in terms of network downloading ability is 2.61 and the standard deviation is 1.22. Network downloading refers to downloading of needed documents, videos, PPT, and software from the vast network to meet the teaching and scientific research needs; the mean value in terms of information processing ability is 2.76 , with a standard deviation of 0.98 . Information processing is a tedious and boring process, and the PE teachers would only feel accomplished and cheered up when this process is combined with teaching and scientific research. The mean value in terms of multimedia making is 3.29 , with a standard deviation of 0.99 . Multimedia making refers to the action of the PE teachers to use computer-based equipment and multimedia making software in teaching, training and scientific research. The mean value in terms of form processing is 3.45 , with a standard deviation of 1.38 . Form processing refers to creation and compiling of obtained data and indexes by the PE teachers in WORD and EXCEL. The mean value in terms of image processing ability is 2.57 and the standard deviation is 1.21 . Image processing refers to analysis of images using a computer to get required results. Twenty First Century is an era of information explosion[12]- [14], and images are the visual foundation for teachers to perceive this world and serve also as an important measure for teachers to acquire and convey information and transmit the information to their students. The mean value in terms of data processing ability is 3.20, with a standard deviation of 1.17. Data processing refers to extraction and derivation of data significant and valuable for teaching and scientific research from chaotic and unreadable data. The mean value in terms of data mining ability is 1.52 , with a deviation of 1.04 . Data mining refers to search of information concealed in the large amounts of data by the PE teachers through computer statistics, online analysis and processing, information retrieval, machine learning, expert system and mode recognition. The overall mean value is 22.90. The indexes are ranked in a higher-to-lower order as follows: Information accessing, form processing, multimedia making, data processing, information processing, network downloading, image processing, and data mining. It can be seen that the comprehensive ability of PE teachers in colleges and universities to use computers is just fair in general. They perform comparatively well in information accessing, form processing, multimedia making and data processing. This is because the PE teachers need to search for related information, input and process some basic data to create forms and finish multimedia making during their teaching and scientific research. However, PE teachers perform poorly in data mining, image processing, network download, and information processing. This is because the overall teaching and scientific research ability of PE teachers are somewhat poor. Data mining takes rich mathematical knowledge and mathematics application ability, and image and information processing takes more abstract thinking. Network downloading takes high skills.

Table 2. Results of Comprehensive Ability to Use Computers

\begin{tabular}{|c|c|c|c|c|c|c|}
\hline Index & $\mathbf{N}$ & Mean value & Standard deviation & Rank & T value & P value \\
\hline Information accessing & 122 & 3.50 & 1.02 & 1 & 37.809 & 0.000 \\
\hline Network downloading & 122 & 2.61 & 1.22 & 6 & 23.621 & 0.000 \\
\hline Information processing & 122 & 2.76 & 0.98 & 5 & 31.147 & 0.000 \\
\hline Multimedia making & 122 & 3.29 & 0.99 & 3 & 36.615 & 0.000 \\
\hline Form processing & 122 & 3.45 & 1.38 & 2 & 27.634 & 0.000 \\
\hline Image processing & 122 & 2.57 & 1.21 & 7 & 23.449 & 0.000 \\
\hline Data processing & 122 & 3.20 & 1.17 & 4 & 30.211 & 0.000 \\
\hline Data mining & 122 & 1.52 & 1.04 & 8 & 16.130 & 0.000 \\
\hline Overall performance & 122 & 22.90 & 8.38 & & 30.186 & 0.000 \\
\hline
\end{tabular}




\subsection{The Comprehensive Ability to Use Computers of Male PE Teachers in Colleges and Universities is Higher than that of Female PE Teachers}

The comprehensive ability to use computers of PE teachers in colleges and universities in Beijing is the highest, followed respectively by that in Shanghai, Jiangxi and Guangxi. Results in Table 3 indicate that: Based on the results of comparison of the comprehensive ability of PE teachers in colleges and universities to use computers by sex, the mean value of male PE teachers is 24.58 , with a deviation of 8.11 and that of female PE teachers is 20.57 with a deviation of 8.27. The mean value for males is 4.01 higher than that for females. It is clear that the comprehensive ability to use computers of male PE teachers in colleges and universities is higher than that of female PE teachers. This is because that the space positioning ability and logical thinking ability of males are stronger than that of the females.

The result of comparison of comprehensive ability to use computers by regions indicates that the mean value of Beijing is 26.89 , with a standard deviation of 6.07 ; the difference between that of Beijing and that of Shanghai is 6.07. The mean value of Shanghai is 26.74 , with a standard deviation of 6.10 . The difference between Shanghai and Jiangxi is 5.39. The mean value of Jiangxi is 21.35 , with a standard deviation of 8.43. The difference between Jiangxi and Guangxi is 5.56. The mean value of Guangxi is 15.79 , with a standard deviation of 7.80 . The comprehensive ability to use computers of PE teachers in colleges and universities in Beijing is the highest, followed respectively by that in Shanghai, Jiangxi and Guangxi. This indicates that the comprehensive ability of PE teachers in colleges and universities to use computers in one region differs greatly from that in another region. The comprehensive ability of PE teachers in colleges and universities to use computers in Beijing and Shanghai is much higher than that in Jiangxi and Guangxi. This is because Beijing and Shanghai are first-tier cities of China and boast colleges and universities of a higher level and also top-ranking teachers.

Table 3. Comparative Analysis by Sex and Regions $(n=122)$

\begin{tabular}{|c|c|c|c|c|c|c|c|c|}
\hline \multicolumn{2}{|c|}{ Index } & N & $\begin{array}{c}\text { Mean } \\
\text { value } \\
\text { (score) }\end{array}$ & $\begin{array}{c}\text { Standa } \\
\text { rd } \\
\text { value }\end{array}$ & $\begin{array}{c}\text { Diffe } \\
\text { rence }\end{array}$ & $\begin{array}{c}\text { Nam } \\
\text { e }\end{array}$ & F value & $\begin{array}{c}\text { P } \\
\text { value }\end{array}$ \\
\hline \multirow{3}{*}{ Sex } & Male & 71 & 24.58 & 8.11 & 4.01 & 1 & 7.137 & 0.009 \\
\cline { 2 - 9 } & Female & 51 & 20.57 & 8.27 & & 2 & & \\
\hline \multirow{3}{*}{ Region } & Beijing & 36 & 26.89 & 6.07 & 0.15 & 1 & & \\
\cline { 2 - 8 } & Shanghai & 27 & 26.74 & 6.10 & 5.39 & 2 & \multirow{3}{*}{16.049} & \multirow{3}{*}{0.000} \\
\cline { 2 - 9 } & Jiangxi & 31 & 21.35 & 8.43 & 5.56 & 3 & & \\
\cline { 2 - 8 } & Guangxi & 28 & 15.79 & 7.80 & & 4 & & \\
\hline
\end{tabular}

\subsection{Ranking of the Comprehensive Ability of $\mathrm{PE}$ Teachers in Colleges and Universities to Use Computers by Age in a Higher-to-Lower Order is as Follows}

The group under 35, the group between 36 and 45, the group between 45 and 55, and the group above 56; the ranking by school age in a higher-to-lower order is as follows: The group of 7 and under 7, the group between 8 and 15, the group between 16 and 23 and the group above 24 .

Results in Table 4 indicate that the in the comparison of comprehensive ability of PE teachers in colleges and universities to use computers by ages and school age, the mean value of teachers under 35 is 27.7 , with a standard deviation of 8.99 ; the difference between this group and the group between 36 and 45 is 3.83 ; the mean value of the group between 36 and 45 is 23.91 with a standard deviation of 7.08. The difference between this group and the group between 46 and 55 is 2.96; the 
mean value of the group between 46 and 55 is 20.95, with a standard deviation of 6.97. The difference between this group and the group of 56 and above 56 is 1.70. The mean value of the group of 56 and above 56 is 19.25, with a standard deviation of 11.49. Ranking of the comprehensive ability of PE teachers in colleges and universities to use computers by age in a higher-to-lower order is as follows: the group under 35, the group between 36 and 45, the group between 45 and 55, and the group above 56. This indicates that the comprehensive ability to use computers of PE teachers in colleges and universities of one age group differs greatly from that of teachers of another age group. In addition, older teachers have lower comprehensive ability to use computers. This is because that the older teachers tend to use computers less frequently than younger teachers. For instance, PE teachers above 46 never used a computer in their college days. When they got older, their comprehensive ability to learn computer skills was retarded.

The results of comparison of comprehensive ability to use computers by school age show that the mean value of PE teachers with school age of less than 7 years is 27.88, with a standard deviation of 5.76; the difference between this group and the group between 8 and 15 years is 1.88; mean value of PE teachers with school age between 8 and 15 years is 26.00, with a standard deviation of 6.418; the difference between this group and the group between 16 and 23 years is 4.89 ; the mean value of PE teachers with school age between 16 and 23 years is 21.11 , with a standard deviation of 7.49; the difference between this group and the group above 24 years is 3.99; the mean value of PE teachers with school age of more than 24 is 17.12 , with a standard deviation of 10.05 . The ranking by school age in a higher-to-lower order is as follows: The group of 7 and under 7, the group between 8 and 15, the group between 16 and 23 and the group above 24. This indicates that the comprehensive ability to use computers of PE teachers in colleges and universities with one school age differs greatly from that of PE teachers with a different school age. In addition, PE teachers with longer school ages tend to have poorer ability to use computers. This is because PE teachers with longer school ages tend to use computers less frequently in their PE teaching and scientific research than PE teachers with shorter school ages. Furthermore, computers have long been absent from PE teaching for a long time in the past.

Table 4. Comprehensive Ability by Age Group and School Age (n-122)

\begin{tabular}{|c|c|c|c|c|c|c|c|c|}
\hline \multicolumn{2}{|r|}{ Index } & $\mathbf{N}$ & $\begin{array}{l}\text { Mean } \\
\text { value }\end{array}$ & $\begin{array}{l}\text { Standard } \\
\text { deviation }\end{array}$ & $\begin{array}{l}\text { Diffe } \\
\text { rence }\end{array}$ & $\begin{array}{c}\text { Nam } \\
\text { e }\end{array}$ & F value & $P$ value \\
\hline \multirow{4}{*}{$\begin{array}{c}\text { Age } \\
\text { grou } \\
\text { p }\end{array}$} & Below 35 & 19 & 27.74 & 8.99 & 3.83 & 1 & \multirow{4}{*}{4.433} & \multirow{4}{*}{0.005} \\
\hline & Between 36 and 45 & 46 & 23.91 & 7.08 & 2.96 & 2 & & \\
\hline & Between 46 and 55 & 41 & 20.95 & 6.97 & 1.70 & 3 & & \\
\hline & Above 56 & 16 & 19.25 & 11.49 & & 4 & & \\
\hline \multirow{4}{*}{$\begin{array}{l}\text { Sch } \\
\text { ool } \\
\text { age }\end{array}$} & Below 7 & 16 & 27.88 & 5.76 & 1.88 & 1 & \multirow{4}{*}{10.362} & \multirow{4}{*}{0.000} \\
\hline & Between 8 and 15 & 43 & 26.00 & 6.418 & 4.89 & 2 & & \\
\hline & Between 16 and 23 & 38 & 21.11 & 7.49 & 3.99 & 3 & & \\
\hline & 24 and above 24 & 25 & 17.12 & 10.05 & & 4 & & \\
\hline
\end{tabular}

\subsection{PE Teachers with Title of Professor have the Highest Ability to Use Computers, Followed by Lectures, Associate Professor and Others}

PE teachers with a doctorate degree have the highest ability to use computers, followed respectively by those with a master's degree, a bachelor's degree and other degrees.

Results in Table 5 show that: In comparison of comprehensive ability to use computers of PE teachers in colleges and universities by titles, the mean value of 
professors are 27.00, with a standard deviation of 5.58; the difference between professors and associate professors is 3.83 . The mean value of associate professors is 21.42 , with a standard deviation of 9.80 ; the difference between professors and associate professors is -3.60 . The mean value of professors is 25.02 , with a standard deviation of 3.82; the difference between professors and associate professors is 6.46 . The mean value of PE teachers with other degrees is 18.5 , with a standard deviation of 7.71. PE teachers with title of professor have the highest ability to use computers, followed by lectures, associate professor and others. This is because that it takes very high teaching and scientific ability for one to be awarded the professorship in China, and he/she must have the comprehensive ability to use computers. Secondly, lectures are young and they have to have the comprehensive ability to use computers to be awarded the associate professorship and improve their teaching and scientific ability. At last, most associate professors believe they are already experts and know clearly about their scientific research level. However, they are content with this. PE teachers with other titles are mostly fresh graduates and senior teachers and trainers with no titles. Most of them are not involved in teaching and scientific research.

In comparison of the comprehensive ability to use computers by academic degrees, the mean value of doctors is 30.38 , with a standard value of 6.67 ; the difference between doctors and masters is 8.04 . The mean value of masters is 22.34 , with a standard value of 7.60; the difference between masters and bachelors is 1.43. The mean value of bachelors is 20.91 , with a standard value of 8.50 ; the difference between masters and bachelors is 3.67. The mean value of PE teachers with other degrees is 17.15 , with a standard value of 7.08. PE teachers with a doctorate degree have the highest ability to use computers, followed respectively by those with a master's degree, a bachelor's degree and other degrees. This indicates that there is a very significant difference among the comprehensive ability to use computers of PE teachers in colleges and universities in terms of academic degrees. It is obvious that a PE teacher with a higher academic degree has a higher ability to use computers. This is because that a PE teacher with a higher academic degree tends to have received more computer related education, especially in the data processing and mining of statistics [17]- [18].

Table 5. Comprehensive Ability by Titles and Educational Background $(n=122)$

\begin{tabular}{|c|c|c|c|c|c|c|c|c|}
\hline \multicolumn{2}{|r|}{ Index } & $\mathbf{N}$ & $\begin{array}{l}\text { Mean value } \\
\text { (score) }\end{array}$ & $\begin{array}{l}\text { Standard } \\
\text { deviation }\end{array}$ & $\begin{array}{l}\text { Diffe } \\
\text { rence }\end{array}$ & $\begin{array}{c}\text { Nam } \\
\text { e }\end{array}$ & F value & $\begin{array}{c}\mathbf{P} \\
\text { value }\end{array}$ \\
\hline \multirow{4}{*}{ Title } & Professor & 16 & 27.00 & 9.35 & 5.58 & 1 & \multirow{4}{*}{4.401} & \multirow{4}{*}{0.006} \\
\hline & $\begin{array}{c}\text { Assoc.profess } \\
\text { or }\end{array}$ & 52 & 21.42 & 9.80 & -3.60 & 3 & & \\
\hline & Lecturer & 38 & 25.02 & 3.82 & 6.46 & 2 & & \\
\hline & Others & 16 & 18.56 & 7.71 & & 4 & & \\
\hline \multirow{4}{*}{$\begin{array}{c}\text { Degr } \\
\text { ee }\end{array}$} & Doctor & 21 & 30.38 & 6.67 & 8.04 & 1 & \multirow{4}{*}{9.952} & \multirow{4}{*}{0.000} \\
\hline & Master & 65 & 22.34 & 7.60 & 1.43 & 2 & & \\
\hline & Bachelor & 23 & 20.91 & 8.50 & 3.76 & 3 & & \\
\hline & Others & 13 & 17.15 & 7.08 & & 4 & & \\
\hline
\end{tabular}

\subsection{The PE Teachers in Colleges and Universities with Paper Level of Foreign Core Paper has the Highest Comprehensive Ability to Use Computers}

The ranking by topic level in a higher-to-lower order is as follows: national level and a higher level, provincial level, municipal level and a lower level. Results in Table 6 indicate that: In the comparison of comprehensive ability of PE teachers in colleges and universities to use computers by the highest level of papers they 
published in the last 5 years, the mean value of provincial level or a lower level is 18.56, with a standard deviation of 6.71; the difference between the provincial level or a lower level and the domestic core paper level is -6.01 . The mean value of domestic core paper level is 24.57 , with a standard deviation of 7.13 ; the difference between the domestic core paper level and the foreign core paper level is -9.74 . The mean value of the foreign core paper level is 34.31 , with a standard deviation of 6.43. The PE teachers in colleges and universities with paper level of foreign core paper has the highest comprehensive ability to use computers, followed respectively by domestic core paper, provincial core paper and papers below provincial level. This indicates that the comprehensive ability to use computers of the PE teachers in colleges and universities differs greatly along with the highest level of the papers published by the teachers. It is obvious that teachers with a higher level of papers have a higher comprehensive ability to use computers. This is because it takes excellent comprehensive ability to use computers for the teachers to publish high level papers.

In the comparison of comprehensive ability to use computers by the highest level of topics finished by the PE teachers in the last 5 years, the mean value of municipal level and a lower level is 21.03 , with a standard value of 7.47 ; the difference between the municipal level and a lower and the provincial level is -6.65 . The mean value of the provincial is 27.68 , with a standard value of 7.94 ; the difference between the provincial level and the national level or a higher level is -9.72 . The mean value of the national level or a higher level is 37.40 , with a standard deviation of 3.13. The ranking by topic level in a higher-to-lower order is as follows: national level and a higher level, provincial level, municipal level and a lower level. This indicates that the comprehensive ability to use computers of the PE teachers in colleges and universities differs greatly along with the topic level. It is obvious that PE teachers with a higher topic level have a higher ability to use computers. Generally only elite PE teachers can get a high topic level. They are not only good at using a computer, but are also able to sort out, plan and innovate in their PE knowledge to declare a high level topic.

Table 6. Comparative Analysis by Level of Papers and Topics $(n=122)$

\begin{tabular}{|c|c|c|c|c|c|c|c|c|}
\hline & Index & $\mathbf{N}$ & $\begin{array}{c}\text { Mean } \\
\text { value } \\
\text { (score) }\end{array}$ & $\begin{array}{l}\text { Standard } \\
\text { deviation }\end{array}$ & Difference & Name & $\begin{array}{c}\mathbf{F} \\
\text { value }\end{array}$ & $\begin{array}{c}\mathbf{P} \\
\text { value }\end{array}$ \\
\hline \multirow{3}{*}{ Paper } & $\begin{array}{c}\text { Provincial level } \\
\text { and a lower } \\
\text { level }\end{array}$ & 55 & 18.56 & 6.71 & -6.01 & 3 & \multirow{3}{*}{30.465} & \multirow{3}{*}{0.000} \\
\hline & $\begin{array}{c}\text { Domestic core } \\
\text { level }\end{array}$ & 54 & 24.57 & 7.13 & -9.74 & 2 & & \\
\hline & $\begin{array}{c}\text { Foreign core } \\
\text { level }\end{array}$ & 13 & 34.31 & 6.43 & & 1 & & \\
\hline \multirow{3}{*}{ Topics } & $\begin{array}{c}\text { Municipal level } \\
\text { and a lower } \\
\text { level }\end{array}$ & 95 & 21.03 & 7.47 & -6.65 & 3 & \multirow{3}{*}{16.974} & \multirow{3}{*}{0.000} \\
\hline & Provincial level & 22 & 27.68 & 7.94 & -9.72 & 2 & & \\
\hline & $\begin{array}{c}\text { National level } \\
\text { and a higher } \\
\text { level }\end{array}$ & 5 & 37.40 & 3.13 & & 1 & & \\
\hline
\end{tabular}

\section{Conclusions and Suggestions}

The comprehensive ability to use computers of PE teachers in colleges and universities is generally low, especially in data mining, image processing, network downloading and 
information processing. The comprehensive ability to use computers of male PE teachers in colleges and universities is higher than that of female PE teachers because the space positioning ability and logical thinking ability of males are stronger than that of the females. The comprehensive ability to use computers of PE teachers in colleges and universities in Beijing is the highest, followed respectively by that in Shanghai, Jiangxi and Guangxi, all of which are first-tier cities of China. Ranking of the comprehensive ability of PE teachers in colleges and universities to use computers by age in a higher-tolower order is as follows: the group under 35, the group between 36 and 45, the group between 45 and 55, and the group above 56 . The ranking by school age in a higher-tolower order is as follows: The group of 7 and under 7, the group between 8 and 15, the group between 16 and 23 and the group above 24. Younger PE teachers and PE teachers with a shorter school age tend to have a higher ability to use computers. PE teachers with title of professor have the highest ability to use computers, followed by lectures, associate professor and others; PE teachers with a doctorate degree have the highest ability to use computers, followed respectively by those with a master's degree, a bachelor's degree and other degrees, PE teachers with a higher title tend to have a higher ability to use computers. However, the appraisal criteria of associate professors used in the past were different from the current criteria and the associate professors are content with things as they are. PE teachers with a higher degree tend to have a higher ability to use computes. The PE teachers in colleges and universities with paper level of foreign core paper has the highest comprehensive ability to use computers, followed respectively by domestic core paper, provincial core paper and papers below provincial level. The ranking by topic level in a higher-to-lower order is as follows: national level and a higher level, provincial level, municipal level and a lower level. PE teachers with a higher level of papers and topics tend to have a higher ability to use computers.

\section{Acknowledgments}

I would like to extend my gratitude to the Subproject titled A Study on Current Situation and Optimized Development of PE Teachers in Colleges and Universities of Guangxi under the key subject titled "A study on Advancing Professional Development of Teachers" of the 12th Five-year Plan supported by National Research Funds for Teachers (No.: GJXI2014822)..

\section{References}

[1] L, Xianghai, N, Yong, and Z, Aijuan, "A Study on Professional Development Strategy of Teachers of Computer Science in Colleges and Universities", Education and Vocation, Vol.24, (2011),pp.83-84

[2] M. Zhendong, "A Brief Analysis of Relation between Implementation of National Fitness Program and PE Reform in Colleges and Universities", Journal of Changji Teachers' College (Comprehensive Version), Vol.3, (2001),pp.65-67.

[3] L. Chunhui, "A Study on Plateau Phenomenon of Professional Development of PE Teachers in Colleges and Universities and Countermeasures", Journal of Chengdu Sport University, Vol.7, (2011),pp.91-94

[4] L. Shu, "An Empirical Study on Destructive Leader and Working Attitude of Subordinates and the Behavior Relationship", Journal of Central South University, (2010),pp.10-13.

[5] X. Aiping, L. Zhiyong, and D. Li, “ Testing of Validity and Reliability of Questionnaire on Employment Stress Coping Styles of University Students", Proceeding of Clinical Medicine, vol.1,(2012),pp.28-31

[6] G. Jing and D. Huichuan, "A Study on JSON Data Transmission Efficiency", Computer Engineering and Design, vol.32,(2011),pp.2267-2270

[7] S. Derong, Y. Ge, "A Summary of Study on NoSQL System Capable of Big Data Management", Journal of Software,vol.24,( 2013),pp. 1786-1803

[8] L. Jinyun, H. Huaijin, and L. Ming, "Design and Implementation of Network Questionnaire System Allowing for Logical Skip and Answer Constraining”,Software Guide, vol.1,(2015 ), pp.107-110

[9] W. Min, "Fuzzy Algorithm in Image Processing and Its Implementation", harming China, vol.10,(2008),pp.56-59

[10] G. Xiuwen, "Application of SPSS Statistical Software in PE “, Beijing: People's Sports Publishing House, (2007),pp.23-28 
[11] Z. Zhenzhen, Z. Junyi, "Comparison between Questionnaries and Network Text Data in Tourism Image Research - With the Research of Tourism Image Perception of Xi'an as an Example”, Zhejiang Social Sciences,vol.12,(2014),pp.73-81

[12] H. Zili, "Forging Die Design Criteria Mining Based on Mathematical Statistics", Journal of Hunan University, (2008),pp.20-24

[13] Z. Zhenbin, D. Jiao, "A Study on Tourism Behavior of Taibai Mountain Backpackers Based on Network Text Content”, Human Geography, vol.1,(2011),pp.134-139

[14] W. Ning, W. Shan, "A Study on Structure of Data Management Curriculum Group and Implementation Scheme," China University Teaching,vol.6,(2010),pp. 62-65

[15] C. Jiangrong, "Strategy to Improve Comprehensive Practical Ability to Use Computers under the "Caseleading and Project-driven" Software Guide,vol.2,(2015),pp. 190-192

[16] R. Juan, L. Hui , “ Exploration into Application of Project Management Method in Employment of College Students",Journal of Fuzhou University,vol,2, (2014),pp. 100-104

[17] L. Dong, Z. Jianli, "Cultivation of Students' Comprehensive Ability in the Project-type Teaching of Computer Specialty under Humanistic Lead”, Computer Knowledge and Technology, vol.12,(2014),pp. 8717-8718

[18] Z. Weimin, Advanced Guide for Visual Basic 6.0,Electronic Industry Press, (2011),pp.10-16. 